\title{
The Effects of Special Economic Zone on Community Health Awareness in Sadao District Songkhla Province, Thailand
}

\author{
Sawpheeyah Nima* \\ Heath System Management Institute. Prince of Songkla University, Hat Yai, Songkhla, Thailand 90110 \\ Virasakdi Chongsuvivatwong \\ The Epidemiology Unit, Faculty of Medicine, Prince of Songkla University, Songkhla Thailand. 90110 \\ Pongthep Suteerawut \\ Heath System Management Institute. Prince of Songkla University, Hat Yai, Songkhla, Thailand 90110
}

\begin{abstract}
Thailand has introduced the policy of Special Economic Zone (SEZ) development to promote trade and investment opportunities in border areas since 2015. However, creating a health awareness strategy prior to SEZ has not been emphasized. This study described the effects of SEZ on community health awareness (CHA) over the period 2017 2018 in Southern border area of Thailand: Sadao District Songkhla Province. Data was collected from 10 groups (151 persons) of 14 community participants by focus group discussion and in-depth interview for developing healthy families, including the growth and stability of each member during SEZ development. The results revealed that promoting awareness of community health issues and preventative action to SEZ was a vital role of themselves to help each other. Not only the engagement of healthcare professionals and health village volunteers, each community was organized themselves to strive in delivering informative, accurate information and assistance. The findings indicated that the prominent policy in promoting a CHA framework is a crucial strategy to enhance sustainability SEZ performance.
\end{abstract}

Keywords: Special economic zones; Community health awareness; Southern Thailand.

\section{(9) () CC BY: Creative Commons Attribution License 4.0}

\section{Introduction}

Special Economic Zones (SEZs) have been established as a strategic instrument for promoting foreign direct investment Myachin et al. (2015) in nearly 4,300 SEZs of 130 developed and developing countries in world wide. As these zones are quite important instrument of socioeconomic development which are in culturally diverse locations with residents, transient, mobile and migrant populations leading to social, environmental and health risks. Because most SEZs are not truly promoting prominent environmental and social features (United Nations, 2015). Besides positive and encouraging, there are also various adverse lessons which other countries should try to avoid in their pursuit of SEZ programs. These are needed to be systematically assessed and effectively managed prior to SEZ for prevention of any suffer in the consequences including unbalance between industrial development and social dimensions (Asian Development Bank, 2018).

According to SEZs are growing globally, Thai government has also been proactive in the development of SEZs and paid attention on border areas with neighboring countries to improve trades and investment locating in 10 different provinces during 2015-2016 in both phases (Community Development Council, 2017). For example, the Songkhla SEZ, mainly for rubber processing and logistics, with a view to growing along with ASEAN's integration. On the other hands, it has not been confirmed yet whether SEZ provides industries with an effective means of development and growth in their health protection in the long run. While the special economic zones have achieved great economic success, the negative impacts are a growing concern. For instance, there are many evidences demonstrating the dark side of SEZ such as waste of resources, environmental damage and health threatening. In this case, deaths, injuries, diseases, disabilities, psychosocial problems and other health impacts can be avoided or reduced by proper management. In order to ensure the smooth functioning of SEZ, a community-driven model designed through mobilization to address health awareness to SEZ is increasing emphasis in world wide.

Community health Awareness (CHA) has been well discussed for encouraging health behavior change (Smith et $a l ., 2016)$ due to its significant role in sustaining improved health outcomes particularly community intervention in health promotion and disease prevention. CHA is also broad responsible for all determinant of health such as socialenvironmental factors including water, sanitation and hygiene intervention (Madon et al., 2018).

When community faces with the various health problems, CHA acts by identifying and to solve them within their community by using the process of enabling communities to increase control over their lives. In order to carry out activities to bring improvement in an individual and environmental health with the help of community members, it needs community member participation. The complex components of CHA are available to positively influence the social dimensions of health and well-being. For example, health knowledge or literacy, health perception, community health database management, community communication and community mobilization are involved 
(Kamaruddin et al., 2016). However, the study about the role of CHA during SEZ program is still limited in over the world.

As there has been increasing recognition that social-environmental factors in SEZ surrounding areas play a critically important role in determining community health status and in causing health disparities. For various global experiences of SEZ happening in many countries including health concern is challenge for Thai people to emerge CHA model that could be applied and scaled up to other areas. Furthermore, an impact of health awareness campaign in improving the perception of the community about SEZ is critically important to place on health communication strategies in Thailand. Thus, the purpose of this study was to explore CHAand their views towards the SEZ and the desire to improve general community health based on effective performance management through capacity building and organizing strategies for a sustainable community along with SEZ in Sadao district, Songkhla province.

\section{Materials and Methods}

This investigation was a descriptive, exploratory qualitative study. The focus group discussions (FGDs) and semi-structured in-depth interview were conducted with the community stakeholders at various locations in Sadao district, Songkhla province during December 2017 to May 2018.

\subsection{Study Participants}

151 Participants were purposively selected from 14 surrounding SEZ communities with the assistance of key persons, who were deeply familiar and involved in the SEZ information in this area at least two years.

\subsection{Study Setting}

This study was carried out in Sadao district, Songkhla province-4 sub-districts including Sadao, Samnak Kham, Samnak Taeo and Padang Besar which is adjacent to Kedah State and Perlis State of Malaysia. (Figure 1) Main 14 tendency communities based on SEZ project at least 2 years were selected and assessed the community health awareness.

\subsection{Data Collection}

The participants were divided into 10 groups based on social status consisting of (1) youths (13-24 years), (2) teachers, (3) health village volunteers, (4) community entrepreneurs, (5) community leaders, (6) healthcare professional personals, (7) religious leaders, (8) foreign workers, (9) local people and (10) Thai workers. Among respondents, the focus groups were made up both of men and women each consisting of 8-10 participants with one moderator and two note-takers who were completely familiar with qualitative research and interview methods. In a one-hour session, the study objective and question guides were explained and then the community health concern prior to SEZ were asked for them to deal with. In parallel session, individual in-depth interview was performed with specific question to generate ideas for improvement and encourage respondents in communicating their underlying attitudes, beliefs and values to CHA to SEZ.

\subsection{Research Tools}

Both semi-structured in-depth interview and focus group discussion were asked the same open-ended questions except the sequence of the questions might vary as well as the level of probing for information by the interviewer.

The semi-structured interviews are characterized by topic guides containing major questions as following:

\subsubsection{Question guides for the Initiation SEZ (2014-2016)}

- What experience do you have when it comes to discussing in recently SEZ in your community?

- What do you know about the impact of SEZ for your local community?

- Could you tell us about how you approach health awareness movement to SEZ?

\subsubsection{Question guides for Progression SEZ (2016-2018)}

- What is required for your community health plan towards to SEZ?

- What have you prepared with regards to community role when it comes to a SEZ in this area?

- What are your community strengths, weaknesses, opportunities and threatening to deal with SEZ?

- What are your expectations to assist the CHA prior to SEZ that you were involved with?

\subsubsection{Question guides for Advanced SEZ (2018-2020)}

- How would you prioritize in catch up your community readiness to SEZ?

- Could you give me an example of your social capital such as resources for CHA model towards to SEZ?

- What are the key features of a CHA model to SEZ?

\subsubsection{Question guides for Ideal SEZ Towards to Sustainable Development Goals (> 2020)}

- Could you tell us about activities you are particularly proud of in your work to deal with SEZ in the future? 
- What techniques are effectively used in raising community awareness and promoting community engagement in health management prior to SEZ?

- How do you make sure you are on the right way to produce a CHA prior to SEZ?

\subsection{Data Analysis}

Socio-demographic information on stakeholder participants was summarized using descriptive statistics. The summary reports were analyzed using thematic analysis. Themes within effects of SEZ on CHA were identified in transcripts and triangulated between communities, difference record sources and with the researcher team to assess consistency, divergence, and validity of themes.

\subsection{Ethical Consideration}

The study protocol was approved by the Health Human Research Ethics Committee of Health System Management Institute, Prince of Songkla University (EC003/61). The participants were also informed about confidentiality and their right to withdraw from the study at any time during the interviews. They agreed to all recording and most of them agreed to being photographed.

\section{Tables and Graphs}

Figure-1. The Songkhla SEZ with total area of 552.3sq.kms. (345,187.5 rai) covers 4 sub-districts along the border area of Sadao district, Songkha province

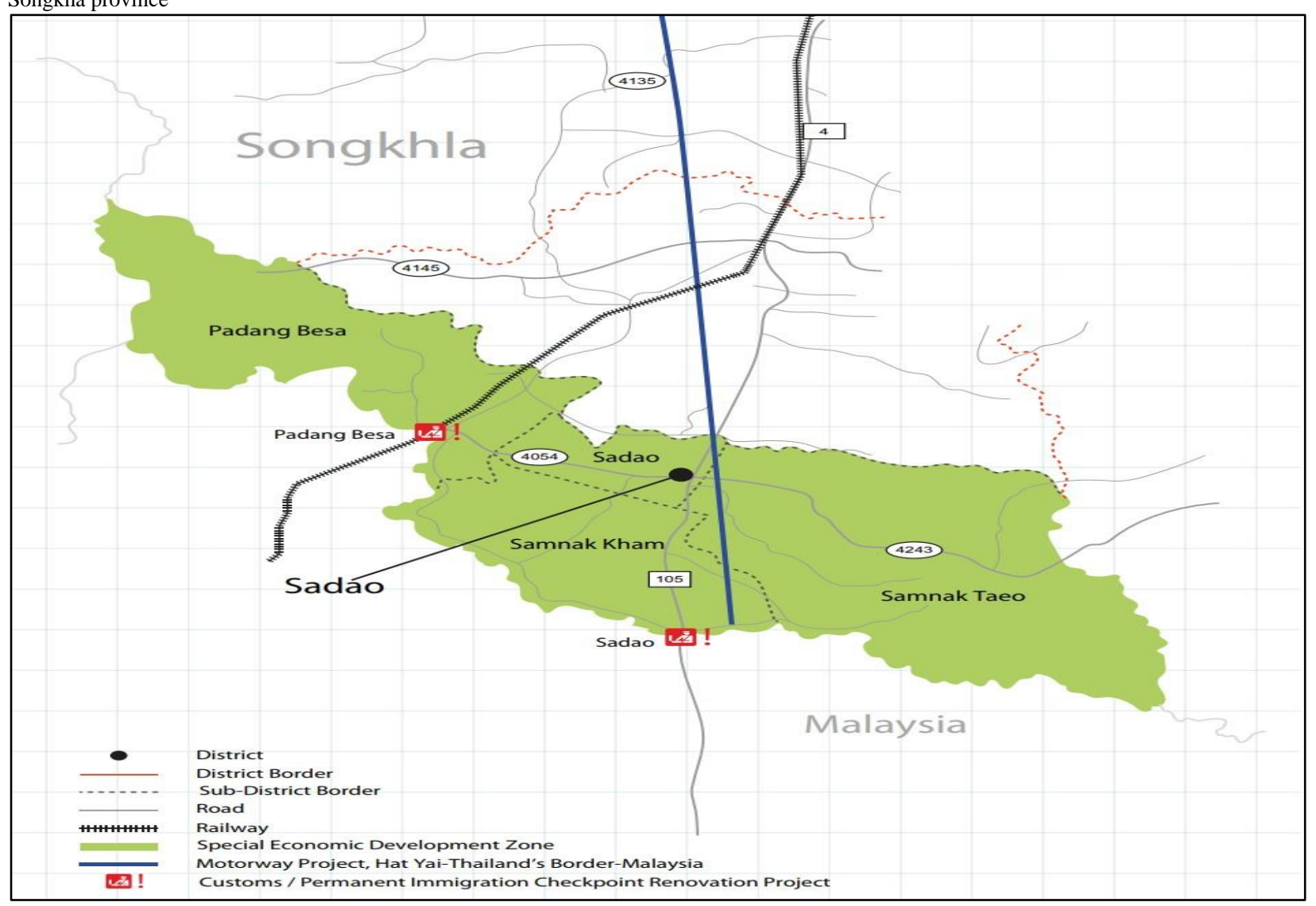

\section{Results}

The participants in this study consisted of majority of women (60.3\%) belonging to age group 25-59 years with the mean age of $37.75 \pm 14.54$ years. About $52.3 \%$ of participants completed secondary level of education. More than half $(60.9 \%)$ were Muslim, and $17.9 \%$ of the participants came from local people. Demographic data of group informants was provided in Tables 1.

The effect of SEZ on the perception of CHA emerged themes that can be categorized into 4 stages based on SEZ stage in Thailand. All participants highlighted 4 common features that need to archive in community health awareness to SEZs. Community stakeholders have expressed that they are willing to become a sustainable community along with SEZ by incorporating the community-driven model that was described in more detail in Table 2 and Figure 2, respectively. 
The Journal of Social Sciences Research

Table-1. Demographic Data of Participants in Both Sessions

\begin{tabular}{|c|c|c|c|c|c|}
\hline \multirow[t]{2}{*}{ Participant Data } & \multicolumn{3}{|c|}{ Total Participants $(\mathrm{N}=151)$} & \multicolumn{2}{|c|}{ Session Groups } \\
\hline & Number & Percentage & Mean \pm SD & FGD & IDI \\
\hline \multicolumn{6}{|l|}{ 1. Gender } \\
\hline Male & 60 & 39.7 & & & \\
\hline Female & 91 & 60.3 & & & \\
\hline 2. Age Group (years) & & & $37.75 \pm 14.54$ & & \\
\hline Youth (13-24) & 33 & 21.8 & & & \\
\hline Adult (25-59) & 107 & 70.9 & & & \\
\hline Elderly (60-80) & 11 & 7.3 & & & \\
\hline \multicolumn{6}{|l|}{ 3. Education Level } \\
\hline Primary School & 20 & 13.2 & & & \\
\hline Secondary School & 79 & 52.3 & & & \\
\hline Higher Education & 52 & 34.4 & & & \\
\hline \multicolumn{6}{|l|}{ 4. Religion } \\
\hline Muslim & 92 & 60.9 & & & \\
\hline Buddhist & 59 & 39.1 & & & \\
\hline \multicolumn{6}{|l|}{ 5. Social Group } \\
\hline (1) Youths & 24 & 15.9 & & $\checkmark$ & \\
\hline (2) Teachers & 16 & 10.6 & & $\checkmark$ & \\
\hline (3) Health Village Volunteers & 21 & 13.9 & & $\checkmark$ & \\
\hline (4) Community Entrepreneurs & 16 & 10.6 & & $\checkmark$ & \\
\hline (5) Community Leaders & 4 & 2.6 & & & $\checkmark$ \\
\hline (6) Healthcare Professional & 8 & 5.3 & & & $\checkmark$ \\
\hline (7) Religious Leaders & 4 & 2.6 & & & $\checkmark$ \\
\hline (8) Foreigner Workers & 13 & 8.6 & & $\checkmark$ & \\
\hline (9) Local People & 27 & 17.9 & & $\checkmark$ & \\
\hline (10) Thai workers & 18 & 11.9 & & $\checkmark$ & \\
\hline
\end{tabular}

FGD= Focus Group Discussion and IDI= In-Depth Interview

Table-2. Stage of SEZ and Community Health Awareness

\section{The development of Special Economic Stage of Community Health Awareness}

\section{Zones (SEZ) in Thailand}

Stage I: Initiation SEZ (2014-2016): They looked back based on the past to set target community health outcomes.

\section{Prepare to mobilize due to probability problems:}

Community members were aiming to improve the quality of life of people in the countryside in term of safe and secure.

They concerned in influx of foreign cheap labors/workers into their communities.

They mentioned about cultural differences will be presented in the workforce compared to their communities.

They were worried about illegal labor and the smuggling of agricultural products from neighboring countries.

They thought the SEZs also face their environmental community damage such as water, food and insufficient energy including hazardous materials.

They showed opinions that SEZ is expected to be an effective tool to make the community's economy move in a positive direction in the future.

They hoped that Songkhla SEZ in the South is close to the sea and has rich forest areas. Therefore, its target industries are agriculture and fisheries, furniture, garments, textiles and leather products, logistics, industrial estates and tourism. These could benefit for their communities.

They mentioned about health opportunities and risks associated with SEZ including tobacco, alcohol and drug abuse smuggling.

They worried about human trafficking in near border regions including communicable or infection diseases.

They were afraid of inadequate health services due to the influx of foreign workers to their communities.

They wondered whether how to solve the problems leading from conflicts between the residents and the SEZ entrepreneurs or project owners.

They needed to see an implementation of mitigation and effective management measures. 


\begin{tabular}{l} 
The development of Special Economic \\
Zones (SEZ) in Thailand \\
\hline \\
Stage II: Progression SEZ \\
(2016-2018): Communities understand the \\
components that currently deliver these \\
outcomes to set a community management \\
plan.
\end{tabular}

They needed to be safe in traffic and road conditions.

Stage of Community Health Awareness

2. Organize the community action with effective performance management:

They set the community forum to exchange a new knowledge about the impact of SEZ.

They wanted to perform the number of actions to improve an accessibility to appropriate health services for Thai and foreign workers including community members.

The expectation of healthcare professional in health risk reduction and can identify SEZ health risks through the initiation of mitigation and well management measures.

In this phase, they wanted to accomplish in collaboration between the community health team, private sector and SEZ officials from other relevant management together.

Health sectors were required to have a critical role to the relevant health data and to respond effectively in proper time.

The community members emphasized that health services and facilities must be available for all people including foreign workers.

The health institutions or academic institutes should be also adequate and easily accessible for the people in SEZ surrounding villages.

The CHA issues were requiring attention.

Stage III: Advanced SEZ (2018-2020): They set priorities based on previous data in dealing with SEZ to develop strengthen model in a next phase.

\section{Stage IV: Ideal SEZ Towards to Sustainable Development Goals (> 2020): They looked towards to the future that needs a monitoring and evaluation for sustainable community.}

3. Community readiness to SEZ using communication and commitment to obtain resources and support for effective action: They hoped that in this phase, people within these SEZ surrounding communities will be essential for maximizing health management opportunities by themselves while identifying and managing health risks for current and future SEZ development.

4. Become to sustainability community throught partnerships and coalitions with public- and private-sector organizations:

They tried to construct the CHA model dealing with SEZ for the next generation that it should be highlighted among political support, collaboration, and community commitments. This strategy will be from the number of government authorities that are required for successful implementation and optimization as a management tool for SEZs in the future.

Figure-2. Stage of SEZ on CHA in Sadao district, Songkhla province, Thailand

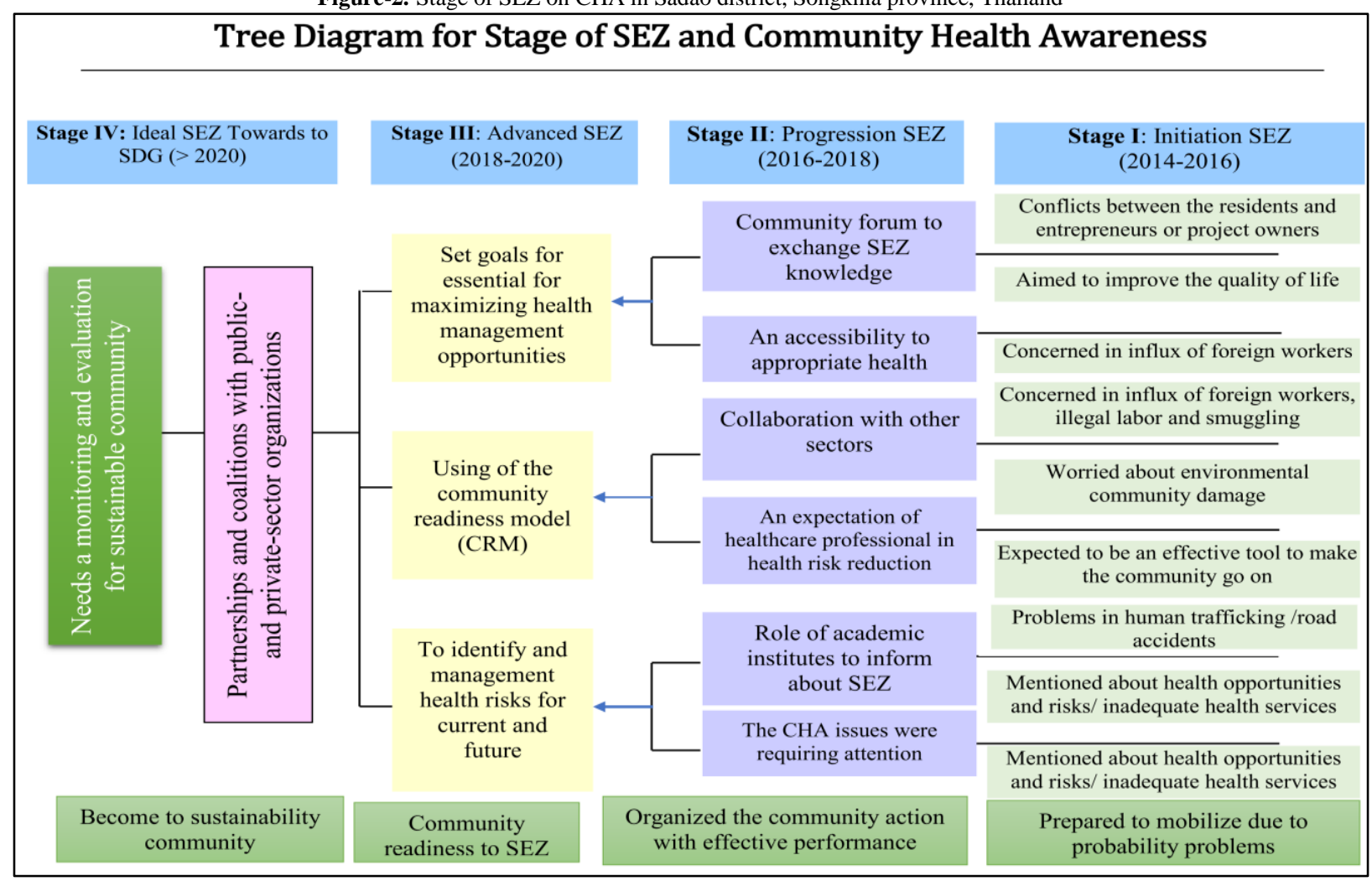




\section{Discussion}

SEZ have been promoted as cornerstone strategies for economic development in Thailand since 2015. There are several studies about SEZ that made attempts to explore investment promotion policy in in the Northern (Uttama, 2014) and explained the expectations of the local population on SEZ in Western Thailand (Teangsompong and Sirisunhirun, 2018). This study tried to investigate the effects of Southern SEZ on CHAby exploring the community perspective views, attitudes and beliefs from the past, present and future. As individuals have their own sense of community members that are beyond the challenge of SEZ. In addition, their sense of membership can change over time and may affect their participation in community activities. Furthermore, CHA is a critical determinant factor for community health management which can empower individuals leading to engagement in collective health promotion action towards to SEZ. For the findings revealed the 4 stages of SEZ on CHA that can be discussed in detail as follows.

\subsection{The Preparation of Community to Mobilization in the Past}

Community mobilization activities within Sadao district, Songkhla province - the first phase in southernmost border areas of Thailand, were spearheaded by community representatives during the initiation of SEZ in 2014-2016. During these period activities, community members and leaders were engaged to identify and address key drivers of community health risks in their communities prior to SEZ together with the local administrative organizations. Fist, community mobilization teams were formed in each community to guide implementation of activities at community level. Knowledge sharing about SEZ and community health was then conducted to shed light on the magnitude and impact of SEZ to their health, social-cultural and environmental dimensions. This step was different from other parts of Thailand that some community members were not involved in determining what worked well and what to scale up toward to SEZ.

\subsection{Organization the Community to Perform an Action at the Present}

In order to enhance their capacity and prepare community to lead mobilization in their districts, local people were trained to follow SEZ news from all kind of medias such as the mass media and social media to catch up themselves to SEZ challenge. Community members and community leaders were always invited to participate the seminar that organized by the local administrative organizations to learn and share the concerns about the new coming of SEZ. In contrast to other SEZ communities in Thailand, there are greater involvement of communitypartners including civil society organizations, NGOs, and activists that work with community in various functions.

\subsection{The Readiness of Community Towards to SEZ in the Next Phase}

An exploration of the health issue was undertaken by the community members and academic institute with utilizing two participatory community tools that were Community Readiness Model (CRM) and community mapping. These methods assisted them to explore how SEZ affects their community health in the long run. For example, community members identified key drivers for dealing with SEZ committee in Songkhla province. The development of action plans was mentioned in monthly community-wide meeting. This channel helped them to inform community members of the planned activities and to invite community input on the plan before finalizing. The action plans were carried out in various ways such as community forums and village sharing discussion. However, these activities were not monitored to make sure whether activities were implemented as planned.

\subsection{The Vision to Become a Sustainable Community Along with SEZ}

The objectives and indicators of success in sustainable community towards to SEZ were also set in some activities particularly what they intend to achieve in the future. However, until now, no any an evaluation committee was formed to feedback or review their objectives and indicators including developed tools to assess progress achieved. Thus, the plan to scale up needed more actions to lead community members to be sustainable community and need more time in scaling up best practices in CHA model to other areas of the SEZ in Thailand.

\section{Limitation}

The most important criterion in selecting these participants were the ability to increase validity of collected data due to their rich of information about SEZ, rather than to ensure that the sample was representative of a population. The present study then illustrates the opinion of the people in FGDs and individual interviews and should for methodological reasons not be generalized to other condition.

\section{Conclusion}

To sum up, although the SEZ of each province all has the same direction, the development of CHA is different. From this exploratory, qualitative study was presented an emerging of CHA towards to SEZ providing abundant evidence about the benefits and possible limitations of SEZ establishing. These findings support the idea that health community awareness should be regarded as a significant tool to voice from below to policy makers in reducing community health risks from SEZ. Therefore, to generate the CHA strategy in other SEZ provinces, this article can be provided as a guideline to achieve. The policy recommendation is that the government should facilitate $\mathrm{CHA}$ through timely access to accurate and locally relevant SEZ information. For further research should address participation action research (PAR) for CHA model in communities surrounding to SEZ in other part of Thailand. 


\section{Conflict of Interest}

The authors did not receive any benefits from the industry or elsewhere to conduct this study.

\section{Acknowledgement}

We would like to thank all participants in this study, who have shared their stories, experiences, and knowledge towards to SEZ in their community. This work was carried out with the aid of a grant from the Thailand Research Fund (MRG6080214).

\section{References}

Asian Development Bank (2018). A health impact assessment framework for special economic zones in the greater mekong subregion. Metro Manila: Philippines.

Community Development Council (2017). Challenges for local economy in the special economic zones. Bangkok.

Kamaruddin, S. M., Ahmad, P. and Alwee, N. (2016). Community Awareness on Environmental Management through Local Agenda 21. 222: 729-37. Available: https://doi.org/10.1016/j.sbspro.2016.05.234

Madon, S., Malecela, M. N., Mashoto, K., Donohue, R., Mubyazi, G. and Michael, E. (2018). The role of community participation for sustainable integrated neglected tropical diseases and water, sanitation and hygiene intervention programs: A pilot project in Tanzania. Social Science and Medicine, 202: 28-37. Available: https://doi.org/10.1016/j.socscimed.2018.02.016

Myachin, D. A., Royzen, A. M. and Pershikov, A. N., 2015. "Regional features of attracting foreign investments into the Russian economy." In Proceedings of The International Conference on Research Paradigms Transformation in Social Sciences 2014 (RPTSS-2014). pp. 131-34.

Smith, S. G., Osborne, K., Tring, S., George, H. and Power, E. (2016). Evaluating the impact of a community-based cancer awareness roadshow on awareness, Attitudes and behaviors. Preventive Medicine, 87: 138-43. Available: https://doi.org/10.1016/j.ypmed.2016.02.034

Teangsompong, T. and Sirisunhirun, S. (2018). Multi-level structural equation modeling for city development based on the expectations of the local population in a special border economic zone in Western Thailand. Kasetsart Journal of Social Sciences, 39(3): 534-41. Available: https://doi.org/10.1016/j.kjss.2017.08.002

United Nations (2015). Enhancing the contribution of export processing zones to the sustainable development goals. An analysis of 100 Epzs and a framework for sustainable economic zones. United Nations Publication: New York and Geneva.

Uttama, N. P. (2014). Investment promotion policy in potential border zone. International Conference on Applied Economics, ICOAE 2014, 14: 615-23. Available: https://doi.org/10.1016/S2212-5671(14)00750-3 